\title{
Higher Education in the New Era
}

\author{
Professor Habibullah Habib. EEM, PhD \\ Kabul University \\ Kabul- Afghanistan
}

\begin{abstract}
S
Learning and changing have eternal bilateral crucial relation with each other. Today's education, especially higher education depends on social equality, economic stability, peacefulness, and good environmental situation. In comparison with the World Declaration on higher education (1998), for our current century Higher education is facing a number of basic important challenges at the local, regional and worldwide (international) level. Currently, globalization is a multifaceted movement that strongly depends on social, economic, cultural, environmental and political implication for higher education. In some countries, the phenomenon of globalization has brought out opportunities and posed the country numerous challenges for the few years in the future. World as a global village not be constrained by national boundaries, it is combined with new technology, media, Trade, and travel. education in the new era an irreversible process that has comprehensive influence role 0n global society, thus our new era strongly needs to provide progressive trends for the new higher education that, should responsible for the demands and new market, because modern knowledge industries encourage many quantities of higher education institutions to participate in competition for obtaining resources and customers.
\end{abstract}

Keywords: New Era, globalization, environment, education system, specialization, strategic alliance, market demands, diversification.

\section{INTRODUCTION}

The twenty-first century calls the era of globalization, this new phenomenon of globalization provided new challenges and valuable opportunities for higher education institutions leaders and their academic staff in term of the different aspect. Since the end of the twentieth century dramatically transformed worldwide communication, trade and economic cooperation. Globalization generalized (Marquardt \& Berger 2003) as a single marketplace with growing free trade among nations and regions. An advanced education and higher educational institution with embedded new technologies must play a pivotal role in knowledge extension, and globalization can support it to share among countries and nations. Based on top trends, 2008-2009 (August 2008) of the Cisco internet business solution group (IBSG) press release, higher education institutions will be able to prepare students to become the next generation of productive employees creative and innovative educated leaders the world needs.

\section{Our Current Society and New Education}

Doubtless, we live in an imperfect world in crisis that everything changes unstable and the knowledge society is ongoing toward in advancing the perspective of trends and improvements. The heterogeneous society is depending to an eternal crisis order to welfare state: for instance, the social, unsustainable practices, the threat posed by globalization, environmental and democracy crisis are the main questions and driver.

The consequences of the above-mentioned crisis including exacerbation of social and economic inequality, the global form of international wide management, decision making the power of individual and government, loss of confidence in the administrative system are foreseeable. 
The capacity for livelong willingness and learning to face new methods and modify learned aspects. In a powerful knowledge, society education is the capacity to create a favorable environment, the capacity to properly manage, the cognitive dissonance and sporadic education toward long live learning. Education for sustainable development (ESD) has emerged as a paradigm for reorientation and revitalization of new education.

Actually, it is a new frame for knowledge and learning how be a human in various way. The principles as per follow are very valuable to transfer for modern education in the new Era. These are: being aware of the challenge creates social change, successfully approaching sustainable development requires, voluntary action taking, collective responsibility assumption, reformulation of construction partnership, believing human dignity, etc. The above-mentioned principles for lasting human welfare, designed at the 2002 world summit on stainable development in Johannesburg. The based on the four pillars of education set out in the Delores Report: Learning to know, learning to do, learning to live together and learning to be. In the contest of SED, UNESCO (2008) suggested the inclusion of fifth pillars: learning to transfer oneself and society. Teaching and learning in the new era need the support of the international organization and international cooperation among higher education institutions in order to share their scientific knowledge production. Furthermore, educational innovation is the key element of the progressive human society and stability toward wellbeing. Demand for educated expert globally increasing phase out and continue to grow. For instance, there are more than 100 million college students worldwide that eager to entry in higher education of an institution. Thus for the, most in need campuses and the educational funding causes the basic questions and proper respond. China, India. The Middle East and some south Asian including developing countries seriously envisage to this situation. Because of the new and modern education, crucial depend on information literary global economy, pedagogical centers with embedded new technologies multilateral cooperation, safety (security) and progressive strategic plans.

\section{The New Era and Challenges of the Higher Education}

At the international level Among all the challenges in the higher education there are some notable points; from them, the two are foreseeable in the focus. First, encouraging international multilateral cooperation between higher educational institutions in term of sharing knowledge and solidity through all inhabitance of the planet. The second is the role of international organizations like UNESCO in advancing the prospection of trends and improvement, promoting networking of fruitful progressive programs (Dobson and Bell, 2006) meanwhile financing issues highly important and pivotal for higher education institutions to carry out their public service function. Women participation in higher education (Universities) has influencing role that foreseeable to access gender equality. Main challenges are faced by higher education institution as per follows:

Take for instance. Change in the educational model, new teaching and learning method to create the ability for proper integration and brainstorming.

- To improve the management of resources in University improves internal democracy, academic and financial freedom, responsibility and dignity.

- Change in the knowledge creation.

- Integrated the potential of communication and information technologies to release knowledge for sharing, and digital wisdom (Prensky- 2009).

In the new Era and knowledge society education is the actual capacity to e productive in an environment of particular uncertainty, the empowerment to considerable manage the cognitive erratic dissonance transfer from sporadic education system towards integrated long live learning system is the preferred priority against to the new era education. 
Globalization also has raised some challenges:

The comparability of quality and standard criteria problem of brain drain, multinationalization of higher education problem of intellectual property and maintaining university as an educational entity (Atkinson 2001, Altbach 2004).

\section{Future Preferred Priorities in higher Education System}

The term of "higher education" covers all forms of studies and training activities at the tertiary level education with encompasses the university offering classical disciplines (Arts and science schools) and specialized branches (Engineering, Agriculture and technology). Consequently, Higher education also consists of all kinds of vocational training entities who have pursued the various form of secondary studies and post-secondary institutions. Recently higher educational organization (university and large profile colleges) in international level are facing three foreseeable major challenges: The first considerable trend is the expansion that refers to the large increase in the number of students in most countries of the world.

Thus Higher education organization in response to public policies providing education to a large portion of the overpopulation based on the banner of "education for all "for instance in some European countries the number of students increased twice (between 1980 - 1995 Austria). The second challenge is diversification.

In some countries like western European developed nations due to the binary system of vocational and higher education organization exist deferent institutions for various target parts (groups) so government or ministries are indispensable to planning to achieve more diverse facilities for these higher education entities.

One of the best examples of diversity in worldwide level is the GONI (global University network for Innovation). Based on GONI press release there are around hundred network and associations are active and pursuing their targets toward new trends in term of higher educations in the new Era.

A third issue is envisaging universities is "massification" which refers to overcrowded and overburdened institutions that are hard to work in, to study in and to properly manage. (Philip G. Altbach, April 1999). Higher education funding strategy, mobility (international reputation) relevance of studies (market demand), a relationship between institution and state, diversity and equal access are the key priority to have them serious attention. New and modern society has been moving toward market demand-oriented higher education system.

The hereby higher education system and related stakeholders can discern a cornerstone of lines of sustainable development as per follow:

- For enhancing globalization we are most in need of acting local and thinking global. This opinion wants to organize a favorable higher education system.

- To create labor and research center in the frame of the higher education system and revise the old model (abandoned) in exchange for building core competencies in applied areas (labor market).

- Institution organization will focus on efficiency, effectively and specialization to response the market demands.

- Embedded require techniques for staying informed about the market demand, economic issues and else other important external variables integrations.

- International mobility and exchange will be important for graduates to improve and strengthen their qualifications, ability, enhance the sophistication of languages and intercultural sensitivity. 
- The new educational system might highly influence organizing networks, conglomerates, strategic alliances, culture, and mergers.

Higher educational organizations are expected to be institutions administered in position with all quality management principles, such as efficiency enterprises, and this entails choices governed by the priority missions. One of the important principal instruments of management consists in preparing a "strategic plan" for the sector that is managed. A strategic plan includes a number of basic elements governing decision making activities to be taken for a determined time.

\section{Enhancing the Validity of the New Higher Education}

Socio-economic situation has significant directory effect on the developments taking place in our society and environment. The economic replacement and globalization process can render possibility as a result of the rapid flow of information, capital feasibility and multilateral free movement of society as well as can support higher education circumstances. Recently new communication and information technologies have influence all aspects of life, including the higher education sector. Invested resources for higher education and compare it is a ratio to outflows in the system, shows the efficiency and effectiveness of the higher education system. Facilities situation, equipment's internal and external effectiveness of the training system. Quantitative human resources are the important criteria of the enhancing validity of the new higher education as well as the knowledge produced in the context of the application, enhanced social accountability, transdisciplinarity, heterogeneity, and organizational diversity, quality control system, are also the basic attributes of the enhancing validation. Furthermore, the higher educational institution might also have to analyze its own internal ability for effectiveness, educational equality comfort, and educational standards. Equal access opportunities, equality of output and equity attributes (indicators) which will enable it to make a self-assessment of all its activities and improve them regularly. Recognized scientific press release (publication) Standard scientific environment, research methodology of activities (training), research appliances can be used properly and membership with some accredited international networks, seriously the preferred priority for enhancing the higher education entities in term of validity. One of the top priorities for enhancing higher educational validity is the physical security and safety as well as collaboration is a basic distinguishing parameter of higher education (universities) in term of accreditation (validation). Because universities are seeking deferent ways to find and facilitate collaboration to research, classes exchange services, private sector partnership, and alumni relationship, to be increased enhance validity. In the new era embedded technology playing a comprehensive increasing role in higher education. Universities will seek innovative ways that will change teaching and learning methodology, realizing new services for current and future technology requires, expandable and secure IT infrastructure (SISCO IBSG-2008).

\section{SUMMARY}

Globalization as an irreversible, inevitable and augmentable process has been significant seriously effects on world society in deferent multilateral aspects. Globalization poses both opportunities and actual challenges for the worldwide level countries higher education system. The fact of globalization means that for any one actor, the bulkily of the knowledge that they will want to use will be produced elsewhere. In Globalization Era, Universities playing major and usefulness roles, in life-long learning and in the evolution of civic culture. In the $21^{\text {st }}$ century, some higher education institutions developed many more and different forms of linkage with the surrounding society. Higher Education in the New Era is a complex competitive and demanding reality. In Globalization Era University leaders and other stakeholders highly need to recognize basic and important challenges and also develop properly strategic plans for managing the changes. A higher educational institution 
(University) in the new Era will only succeed that able to conduct and manage major challenges and affirmative changes efficiently and effectively.

\section{References}

Altbach. P. G. (2004). Globalization and the University. Myths and Realities in an Unequal world. Boston, Boston College.

Bloom. D.E. (2002). Mastering Globalization: from Ideas to action of Higher Education Reform. Hayward, Hayward University.

Michael Gibbons (1998). Higher Education Relevance in the $21^{\text {th }}$ Century.

Orr. (2004).Earth in Mind: on education, environment and the human prospect, Chicago, Island press, $2^{\text {nd }}$ Education.

Philip G. Altbach, Patti Me Gill Peterson (April 1999). Higher Education in the $21^{\text {th }}$ Century: Global challenge and national Response.

Sace. J. (2005). Managing Organization in a global economy: An intercultural perspective Ohio: Thomson-SouthWestern.

Starling. S. (2001). Sustainable Education: Previsioning learning and change, Schumacher Briefings 6, Green Books, London.

Tracey Eilen-Daugenti and Alva Grace McKee (Augest-2008).

Uralic-Trumbic. S. (2003). Higher Education in a Globalized Society: UNESCO Education Position paper, viewed 25 July 2006

UNESCO (2008). Education and the search for a sustainable future, policy Dialogues: ESD and development policy. 